\title{
Wika Salim
}

\section{Adib Rifqi Setiawan}

Alobatnio Research Society $(\Lambda \mathrm{RS})$

Jl. Kudus - Colo km. 19, Pandak 001/003, Colo, Kudus, 59353, Indonesia

adibrifqisetiawan@gmail.com

\begin{abstract}
Abstrak
Kisah Wika Salim yang tak lelah mengayuh misteri teranyam azam. Teranyam sebagai motivasi dan inspirasi agar tetap meniti tatanan dari Sang Pencipta Semesta Raya dengan rasa riang. Wika terlahir sebagai penghibur, yang sanggup membuat orang lain gembira meski dia sendiri tak selalu merasakannya. Sanjungan yang diterima tak membuat Wika melayang. Begitu juga cibiran tak membuat dirinya tumbang. Wika tetaplah Wika, yang kehadirannya selalu dirindukan, namanya dielu-elukan. Dan, dia tetaplah perempuan, yang selalu sulit untuk dimengerti sepenuhnya meski dapat dinikmati seutuhnya. Wika ketika dilihat itu fisik, ketika dinikmati itu hati.
\end{abstract}

Kata-kata Kunci : Dangdut; Musik; Model; Penghibur; Penyanyi;

\section{A. Pengantar}

Musik adalah pengungkapan gagasan melalui bunyi yang mengalun secara teratur sehingga enak untuk disimak (al-Fārābī, 1967, hal. 47). Pada zaman kuno, terdapat mitos dari sekelompok masyarakat yang percaya bahwa musik memiliki kekuatan ajaib untuk menyempurnakan jiwa dan raga (McNeill, 2000, hal. 2). Pada zaman now, terdapat anggapan bahwa musik mempunyai kekuatan untuk mencirikan pandangan pribadi dan kecenderungan masyarakat (Prasetyo, 2012). Menyimak berbagai jenis pertunjukan musik di Indonesia, barangkali dapat dikatakan bahwa tidak ada yang lebih meriah dan meriak dibandingkan dengan dangdut. Hal ini bisa diamati melalui tulisan, tuturan, dan tayangan di beragam media massa, perbincangan di lingkungan pergaulan, maupun membludaknya para pengunjung yang menghadiri pertunjukan tersebut. Sulit dimungkiri bahwa dangdut dapat menarik perhatian banyak kalangan.

Dangdut, di satu sisi, terbilang mudah menjamah manah masyarakat, khususnya buat yang sedang dalam kesulitan (Weintraub, 2010, hal. 145). Larik lirik dangdut yang banyak memuat kisah tentang pergulatan pribadi dalam berjuang di tengah kehidupan sosial yang kadang timpang seakan menjadi penyalur rasa terpendam (David, 2014, hal. 258). Di sisi lain, dangdut sering dicibir karena dianggap tidak bermutu (Weintraub, 2006, hal. 411). Apalagi dangdut terbilang lentur, tak kaku untuk berpadu dengan beragam pengaruh yang tumbuh dalam dunia olah rasa, mulai dari nada ala Timur sampai Barat, tingkat ndeso hingga dunia (Wallach, 2014, hal. 272-3).

Cibiran terhadap dangdut kian meriak tatkala fenomena goyangan erotis penyanyinya semakin marak. Goyangan erotis sendiri sebenarnya bukan fenomena baru dalam pertunjukan musik dangdut. Keberadaan penyanyi dangdut dengan goyangan erotis sudah muncul sejak dekade 1970-an, tetapi kala itu hanya terbuka untuk kalangan dewasa belaka (Fitriya, 2018, hal. 1). Perbedaan tajam mulai terjadi pada dekade 2000-an, ketika goyangan erotis menjadi sajian biasa nyaris di setiap pertunjukan, baik on maupun off air (Weintraub, 2010, hal. 164 \& 188). Masyarakat yang sejak dulu menganggap bahwa goyangan erotis sebagai perbuatan tabu pun mulai bereaksi secara menggebu. 
Keadaan sejenis demikian membuat penyanyi dangdut perempuan (biduanita) belakangan ini mudah mendapat nilai plus dan minus dalam berkarier. Kemudahan mendapat perhatian dan mencerna larik lirik yang dilantunkan serta alunan nada yang disajikan membuat para biduanita gampang dikenal oleh banyak kalangan. Hal ini memudahkan biduanita untuk meluaskan pergaulan, menambah wawasan, hingga menggunakannya sebagai sarana menambang uang. Sayangnya, biduanita juga kerap dinista karena dianggap hanya menjual penampilan badan tanpa peduli kualitas vokal. Sebenarnya tak ada masalah dalam menjual penampilan badan, masalahnya ialah hal ini dilakukan di pasar yang menjajakan vokal.

Keadaan tersebut disadari sepenuhnya oleh Wika, penyanyi kelahiran Bogor, Indonesia, yang memilih dangdut sebagai jalan karier untuk ditekuninya. "Mungkin untuk orang-orang yang sebenarnya mereka bukan basic-nya penyanyi dangdut, tapi hanya sekadar mau cari uang di dangdut dan tidak menjaga nama baik dangdut ya itulah yang merusak," ungkap Wika tentang kesedihannya ketika dangdut yang sudah mulai dipandang baik ada saja yang membuatnya kembali jelek (Puspasari \& Syaifullah, 2019). "Mereka yang membawa dangdut dipandang sebelah mata adalah orang-orang yang nggak ngerti dangdut, bukan orang dangdut, tapi pengin cari uang di dangdut dan caranya salah. Yaitulah dangdut jadi jelek. Aku sedih, karena termasuk yang cinta banget sama dangdut. dangdut ini bukan yang lo lihat sebelah mata, seronok, murahan, itu hanya oknum-oknumnya saja. Secara musiknya saja, dangdut itu adalah musik yang mahal. Secara nggak semua orang bisa nyanyi dangdut," tambahnya.

Wika bukanlah pendatang baru dalam belantika musik dangdut Indonesia. Penyanyi dangdut yang dikenal dengan 'Goyang Keramas' merupakan peserta ajang kompetisi pencarian bakat yaitu StarDut di Indosiar 2008 silam. Ketika itu, dirinya berhasil menjadi finalis. Menjadi penyanyi merupakan upaya Putri bungsu dari pasangan Agus Salim dan Mujiarti untuk bisa membahagiakan dan menjadi kebanggaan kedua orangtua. Pasalnya orangtua Wika memiliki mimpi anak sulung mereka bisa menjadi salah satu penyanyi dangdut papan atas. Karena itulah dalam usaha pencapaian mimpi yang banyak mengalami rintangan, semangatnya untuk terus berusaha mewujudkan.

Berdasarkan latar belakang tersebut, kami tertarik untuk menulis biografi Wika. Bentuk penting dari auto/biografi ialah menampilkan dokumen cerita faktual mengenai perjalanan seseorang yang berpotensi untuk dijadikan panutan (Stanley, 1992, hal. 11 \& 14). Auto/biografi juga mempunyai potensi untuk menjadi agen perubahan di satu sisi dan pelestarian nilai sosial tertentu di sisi lain (Steedman, 2000, hal. 27). Auto/biografi memang ditulis tentang seseorang tertentu, tetapi hasilnya tidak hanya bisa dinikmati oleh penulis atau sosok dalam auto/biografi, melainkan oleh publik untuk dimaknai sebagai bagian perbincangan tentang kehidupan pada umumnya (Bruner, 1993, hal. 41; Nadel, 1986, hal. 1).

Walau kerap dianggap remeh, auto/biografi merupakan bagian penting dari budaya yang mencerminkan cara mengapresiasi diri, menampilkan sejarah, dan menunjukkan perubahan. Dari pengamatan yang dilakukan, kami melihat belum terdapat biografi utuh mengenai Wika. Sebagai tokoh publik yang memiliki banyak penggemar, informasi utuh tentang Wika perlu disediakan. Apalagi Wika memiliki rekam jejak kontroversial, yang tak jarang menjadi sasaran ejekan maupun kabar yang masih belum jelas ketepatannya. Dirinya jarang dinilai berdasarkan karakter yang ditampilkan maupun karya yang disumbangkan, meski dua hal ini melekat pada dirinya. Justru rasa sinis dan pandangan sempit kerap menjadi landasan dalam mengomentari diri maupun langkah perempuan kelahiran 26 Februari 1992 ini. 


\section{B. Metode}

Penelitian yang dilakukan bertujuan untuk mendapat narasi biografi Wika. Karena itu, diperlukan data terkait, seperti personalitas, identitas, pengalaman, karya, dan gaya dari Wika. Berdasarkan tujuan yang ditentukan dan data yang dibutuhkan, metode penelitian yang dipilih ialah kualitatif (Fraenkel \& Wallen, 2009, hal. 422-3).

Kemudahan penggunaan metode kualitatif ialah tidak diperlukan tindakan untuk mengutakatik fenomena. Sedangkan kesulitannya ialah mengutamakan gambaran utuh dari fenomena. Dari penuturan kemudahan dan kesulitan, metode kualitatif dipilih karena kami bermaksud memahami secara menyeluruh dari fenomena yang diteliti. Fenomena tersebut ialah diri Wika sebagai seorang pribadi dan tokoh publik. Sehingga di sini, kami berperan sebagai instrumen penelitian.

Dari metode yang dipilih, pendekatan yang digunakan ialah naratif (Fraenkel \& Wallen, 2009, hal. 427). Pendekatan naratif memperbolehkan partisipan untuk menyebutkan kembali beberapa peristiwa untuk ditafsirkan oleh peneliti sebagai bahan penggambaran. Karena penyebutan itu terkait dengan pengalaman orang, maka bentuk yang dipilih ialah kajian biografi. Pada bentuk ini, penelitian fokus pada penafsiran beberapa peristiwa yang dialami oleh satu individu untuk digambarkan melalui narasi.

Partisipan sebagai sumber data dipilih menggunakan teknik purposive sampling (Fraenkel \& Wallen, 2009, hal. 99 \& 426). Sumber utama dalam penelitian ini ialah Wika. Sedangkan sumber pendukung ialah rekaman, seperti catatan, artikel, foto, audio, dan video serta tuturan sumber lain terkait Wika.

Data tersebut dikumpulkan menggunakan teknik wawancara (Fraenkel \& Wallen, 2009, hal. 445-6). Wawancara dilakukan secara informal untuk mendapat tuturan ingatan partisipan terhadap beberapa peristiwa yang dialami terkait fokus penelitian. Dengan demikian, tipe yang digunakan ialah wawancara retrospective.

Data yang didapat berdasarkan ingatan, sehingga perlu diperiksa keabsahan dan keandalannya. Pemeriksaan ini dilakukan menggunakan external audit (Fraenkel \& Wallen, 2009, hal. 453). Karena itu data yang diperoleh tidak langsung digunakan, melainkan diulas dan dinilai oleh orang lain di luar peneliti dan partisipan lebih dulu, untuk didapat data yang absah dan andal. Data yang absah dan andal tersebut kemudian dianalisis dan disintesis secara deskriptif untuk mendapat gambaran yang saling terkait.

\section{Hasil}

\section{Sejak kapan punya rambut pendek dan alasannya?}

Rambut pendek itu kalo nggak salah, awal tahun 2017. Kenapa rambut pendek? Satu, karena dulu aku tuh hampir 5 tahun lebih rambutnya panjang terus dan selalu hitam. Pengen sesuatu yang baru aja gitu kayanya bosenih, akhirnya kepikiran untuk coba potong pendek.

\section{Apa job pertama kamu?}

Pertama kali tuh aku nyanyi pas acara hajatan di daerah ciracas. Kayanya itu pas aku SD, kira-kira kelas 3. 
Berapa sih bayaran pertama saat kamu jadi penyanyi?

Aduh lupa gue, berapa ya hahaha. Sekitar 50 ribu sampe 75 ribu lah pokonya.

\section{Ada rencana bikin bisnis?}

Kalo bisnis sejauh ini belum aku jalanin, tapi kalo kepikiran sih udah. Aku kan suka fashion, jadi aku tuh kepikiran pengen bikin baju atau kaos-kaos yang memang aku banget, rencananya.

\section{Apa kejadian yang tak terlupakan buat kamu?}

Kejadian yang paling nggak bisa dilupain yaitu waktu aku nyanyi di Belitung. Jadi pas selesai nyanyi, turun dari panggung, itukan rame banget masih banyak penonton yang banyak belum pulang. Terus ceritanya aku mau turun, dan posisinya udah dijagain banget. Tiba-tiba pas aku mau pegangan tangga, ada yang narik tangan aku dari atas, jadi aku jatoh guling-guling gitu dari tangga panggung yang lumayan tinggi. Saat itu aku lagi pake sepatu boots, sepatunya patah bagian depannya rusak, kaki aku juga jadi keseleo. Udah gitu, orang yang mau salaman kabur dan ilang nggak tau kemana. Mungkin dia takut kaliya, soalnya tadinya dia mau salaman tapi ketarik dan bikin aku jatoh. Akhirnya aku pulang naik pesawat nggak bisa pake sendal karena kaki aku bengkak.

\section{Bagaimana rasanya dampingi Tukul Arwana di acara Ini Baru Empat Mata?}

Rasanya seneng banget, excited nggak sabar karena program yang ditunggu-tunggu masyarakat juga. Kemarin aku sempet posting di Instagram promo program ini, walau belum dibilang itu programnya tapi di frame ada Mas Tukul terus orang-orang udah notice gitu 'wah kayaknya ini empat mata ada lagi' dan respon dari temen-temen di instagram itu antusiasnya luar biasa. Jadi yang pastinya aku bersyukur banget karena banyak banget co host yang lebih baik dari aku, lebih berpengalaman, tapi alhamdulillah di sini temen-temen Trans 7 ngasih tempat untuk aku asah lagi kemampuan aku. Semoga ini jadi program yang kembali fenomenal.

\section{Terlibat di sana jadi batu loncatan karier kamu?}

Memang dari sebelum-sebelumnya orang yang bekerja sama dengan mas Tukul gitu (sukses) ya, alhamdulillah menjadi lebih baik dan jalannya terbuka lebar. Mudah-mudahan ini jadi satu kesempatan untuk aku juga (sukses) dan membuktikan aku juga mampu bekerjasama dengan mas Tukul.

\section{Ceritain dong bagaimana tawaran itu datang.}

Jadi emang gini, sebenernya ada banyak banget, ada beberapa kandidat yang menjadi pilihan untuk jadi co host mas Tukul. Aku salah satunya, terus ditawarin, dateng, kita tes, ya aku nothing to lose ya, yang penting aku udah coba, karena memang ini kan salah satu program unggulan trans 7 jadi aku coba dan aku dapet kabar. Seneng banget karena prosesnya emang nggak terlalu lama. Aku dateng, kita tes ketemu mas Tukul dan nanti jalan (program). Mas tukul kan suka bercanda gombalan apa ya, mas tukul tuh spontan jadi apapun nanti yang terjadi karena kita emang kerjasama kita ambil positifnya aja

\section{Jadi presenter bakal meninggalkan dunia tarik suara nih?}

Nggak dong, karena kan nyanyi tetep bisa jalan. Dan di program ini nggak menutup kemungkinan aku masih punya wadah untuk bisa nyanyi. Jadi nyanyi tetep, co host juga. Jadi ya kayak memperlebar pekerjaan aku. 


\section{Terus sekarang masih terima tawaran main FTV atau sinetron?}

Nggak sih, selama waktunya ketemu. Pokoknya semua kembali ke schedule, kalau bisa diatur ya aku masih tetep jalani semuanya.

\section{Semua bidang sudah dilakoni. Memang mau terkenal seperti apa sih?}

Sebenernya kayaknya lebih enak disebut multitalenta ya. Hem, nggak juga sih, aku sampai sekarang masih banyak belajar. Awalnya sih aku nyanyi ya.. tapi makin ke sini aku banyak belajar dan pengin coba segalanya. Kalau dibilang pengin yang mana? Pengin semuanya. Tapi karena aku pertama kali di entertain nyanyi jadi aku nggak akan meninggalkan dunia nyanyi

\section{Pembahasan}

Wika adalah salah satu manusia yang berani berunjuk rasa (expression) dengan cara yang bisa dilakukannya (Darwin, 1872, hal. 10). Keberanian berunjuk rasa menjadi satu hal yang memang selayaknya dilatih sejak masa balita. Keberanian berunjuk rasa memberi semangat agar tak ragu mengungkapkan perasaan dengan penuh yakin diri (confident) (Stajkovic, 2006, hal. 1209). Yakin diri menjadi pondasi penting dalam membentuk jiwa yang rendah hati (Davis, et al., 2011, hal. 225). Manusia yang piawai berunjuk rasa memiliki dua sisi berkelindan ini: yakin diri dan rendah hati. Meski seringkali yakin diri dilihat sebagai arogansi dan rendah hati dinilai sebagai wujud rendah diri.

Walau unjuk rasanya menggembirakan rasa maupun melepas lara manusia lainnya, Wika tetaplah manusia biasa. Wika butuh makan, minum, maupun tidur, juga bisa berpeluh lelah, berkeluh kesah, berkeruh amarah, merasa bad mood, minder, dsb. dst. laiknya manusia pada umumnya. Kepiawaian Wika dalam berunjuk rasa dengan berbagai cara tetap disertai pembawaan diri dalam menjalani keseharian laiknya manusia biasa. Sepanjang menjalani keseharian, Wika tak pernah meminta dikagumi. Dirinya hanya berusaha melakukan perbuatan yang selaras nurani. Walakin dari sini, banyak orang yang kemudian mengagumi Wika. Tak sedikit pula yang menjadikan perempuan kelahiran Jumu'ah Pahing ini sebagai panutan untuk dianut.

Wika sendiri tak memikirkan hal tersebut. Dikagumi atau tidak, menjadi panutan atau bukan, tak menjadi pijakan Wika. Wika hanya berusaha untuk terus tetap mentas, tanpa mencari pencapaian, tanpa lelah berjuang. Di-reken sukses atau tidak dalam pencapaian bukan urusannya, yang merupakan kesuksesannya adalah tak lelah berjuang mengayuh secara terusmenerus. Mengayuh... mengayuh... mengayuh perjalanan... saling mengapresiasi kesamaan dan menghormati ketidaksamaan... "You say God give me a choice..." seperti lantun Queen dalam Bicycle Race (Queen, 1978).

Wika tak lelah berjuang bukan semata memuaskan hasratnya, tidak juga sekadar menggembirakan ortangtua, melainkan untuk memberi motivasi dan inspirasi buat sesama manusia biasa, khususnya anak-anak yang merasakan perih dan pedihnya menerima perpisahan. Wika mengajak kita semua untuk menyadari bahwa setiap orang sudah memiliki jalannya sendiri, walau masih misteri, tak bisa dilihat secara pasti. "Life is a mystery..." lantun Madonna dalam Like a Pray (Madonna, 1989). Perjalanan yang dilakoni Wika adalah duet awet ikhtiar dan takdir. Sebagian orang boleh saja memandangnya dengan cemar dan rajin mencibir. Meski demikian, Wika tak langsir ungkapan nyinyir yang dialamatkan padanya dari para tukang pandir. Biarpun sebagian orang sirik tiada akhir, Wika terus tetap mengalir. 
Di luar sisi sebagai workaholic, Wika tetap bersemangat saat terlibat obrolan, membaca buku, serta jalan-jalan. Sembari mengayuh perjalanan selaras nuraninya, dia pun terus melantan rasa cinta pada orangtua, keluarga, dan orang-orang dekatnya. Wika tak setengah hati menggeluti industri hiburan, untuk melampiaskan hasrat seni maupun meraih keuntungan finansial. Dengan tetap menyadari keuntungan dan kerugian yang didapatkan, Wika terus menjalani dengan penuh gairah membuncah. Sekarang penggemar musik 1950-80 an ini seakan mengayuh perjalanan yang membuat namanya memiliki harga jual. Kehadirannya pun dapat memiliki nilai komersial. Keadaan yang demikian tentu memudahkannya untuk ikutserta dalam berbagai kegiatan sosial.

Tak dimungkiri bahwa kecantikan turut berperan dalam perjalanan Wika. Karena kecantikan ini pula Wika banyak mudah mendapatkan cibiran, seperti 'modal cantik doang'. Pertanyaannya, salahkah menjadi perempuan cantik? Sebagian orang mungkin akan menjawab iya (Zein \& Setiawan, 2019). Naomi Wolf menuturkan bahwa kecantikan adalah mitos yang diciptakan industri untuk mengeksploitasi perempuan secara ekonomi melalui produk-produk kosmetik.

Pandangan Naomi beserta pendukungnya boleh jadi tidak bisa disalahkan, namun kurang lengkap untuk menjadi genggaman. Pasalnya Naomi tak mementingkan paras cantik sebagai salah satu modal untuk perempuan, seperti diungkapkan oleh Catherine Hakim melalui konsep erotic capital (modal erotis). Erotic capital merupakan kombinasi dari daya tarik fisik, estetik, visual, sosial, dan seksual yang dimiliki seseorang untuk menarik orang lain (Hakim, 2010). Ada enam bagian dalam erotic capital, kecantikan adalah salah satunya. Sepertihalnya jenis modal lain, erotic capital juga dapat diupayakan, kosok bali dengan pandangan yang cenderung menyangka bahwa kecantikan hanyalah ketetapan Tuhan atau suatu kebetulan alamiah.

Cibiran terhadap Wika yang turut memanfaatkan kecantikan, banyak berpijak dari pandangan yang menyebut bahwa pintar adalah hasil tekun belajar, sedangkan cantik adalah bawaan lahir. Cerdas dianggap sesuatu yang diperoleh lewat kerja keras, sedangkan kecantikan adalah anugerah yang didapat tanpa usaha. Padahal posisinya bisa saja terbalik. Pasalnya faktor genetis pun, terutama dari ibu, berperan penting dalam menentukan kecerdasan seseorang. Sedangkan untuk tampil cantik, seseorang perlu banyak berusaha, mulai dari olah raga, menjaga pola konsumsi, merias wajah, hingga berpikir menentukan pakaian.

Tak perlu membutakan mata menyaksikan bahwa orang yang cantik memang kerap mendapat beragam kemudahan. Contoh paling bagus dalam hal ini ialah Maria Yuryevna Sharapova (Maria Sharapova) (Badenhausen, 2016). Pendapatan sebagai model jauh lebih banyak ketimbang menjadi petenis. Maria bahkan masih tetap menambah kekayaan saat diskors garagara kasus obat-obatan terlarang. Nilai penting erotic capital setara dengan modal lain seperti ekonomi, sosial, dan budaya.

Pertanyaan selanjutnya, mengapa kita tampak enggan mengapresiasi kecantikan perempuan sepertihalnya kecerdasan? Ketika ada perempuan dandan, dibilang menghabiskan waktu tak berguna. Walakin ketika membaca buku, disangka waktu diisi dengan kegiatan bermanfaat. Perempuan yang berusaha menunjukkan kecantikan malahan tak jarang otomatis dianggap bodoh. Pekerjaan yang menjual badan perempuan, seperti modelling, diberi stigma sebagai pekerjaan hina. 
Lebih menyesakkan lagi, ketika ada perempuan cantik ingin menikahi lelaki kaya dilabeli 'matre' yang mengkhianati kesucian cinta dalam perkawinan. Padahal, alasan di balik julukan 'matre' ini adalah bahwa lelaki harus mendapatkan kenikmatan yang mereka inginkan dari perempuan secara gratis, terutama seks (sex).

Kecantikan dan upaya mempercantik diri dianggap sebagai tindakan tak baik. Para peserta kontes kecantikan, misalnya, mendapatkan banyak cibiran. Kecerdasan dan kecantikan dilihat sebagai dua hal bertentangan yang tak mungkin dipadukan oleh perempuan. Perempuan yang memiliki keduanya, tidak diizinkan untuk menggunakan semuanya, hanya boleh memaksimalkan kecerdasan saja. Mengapa oh Menyapa? Whyyy?

Dengan memperhatian perdebatan wacana pemanfaatan badan perempuan tersebut, Wika patut diapresiasi semadyana sebagai perempuan yang menggunakan kecerdasan dan kecantikan. Sah-sah saja kalau Wika rajin merawat badan, terutama payudara dan pantat, bagian yang memiliki daya pikat kuat dalam merangsang gairah seks lelaki (Setiawan, 2018).

Seks terbilang nafsu yang paling sosial (Setiawan, 2018). Tanpa memperhitungkan moral, secara naluriah kita bisa turut bergembira menyaksikan orang lain yang sedang memenuhi nafsu seksnya. Kita punya hasrat kesenangan walaupun sekadar untuk menontonnya. Itulah kenapa ada pornografi, yang melahirkan industri seperti blue film (BF) dan majalah dewasa dengan omzet besar.

Seks berbeda dengan nafsu lain, misalnya nafsu makan. Adakah orang, terutama lelaki, yang sanggup suntuk berjam-jam menyaksikan tayangan dengan sajian berupa adegan-adegan orang sedang makan bakwan biarpun orang itu adalah Cania Citta Irlanie? Adakah media pendulang iklan yang menjebak pengunjung dengan gambar Oza Kioza sedang mangap ngemplok cilok?

Saking sosialnya nafsu yang satu itu, ia jadi begitu canggih buat menyedot perhatian. Ia jadi empuk sebagai bahan berita dengan judul-judul menggemaskan. Ia juga legit buat stok pengalihan isu, yang bisa dengan gampang ditembakkan sewaktu-waktu. Sebab, kabar terkait seks tidak cuma memberikan informasi, walakin memberdayakan imajinasi. Wika menyadari sisi ini, mengerti hal ini. Tak risau dengan segala caci-maki maupun puja-puji, dirinya berusaha memanfaatkannya memenuhi kebutuhan diri.

\section{E. Penutup}

Kisah Wika yang tak lelah mengayuh misteri teranyam azam. Teranyam sebagai motivasi dan inspirasi agar tetap meniti tatanan dari Sang Pencipta Semesta Raya dengan rasa riang. Wika terlahir sebagai penghibur, yang sanggup membuat orang lain gembira meski dia sendiri tak selalu merasakannya. Sanjungan yang diterima tak membuat Wika melayang. Begitu juga cibiran tak membuat dirinya tumbang. Wika tetaplah Wika, yang kehadirannya selalu dirindukan, namanya dielu-elukan. Dan, dia tetaplah perempuan, yang selalu sulit untuk dimengerti sepenuhnya meski dapat dinikmati seutuhnya. Wika ketika dilihat itu fisik, ketika dinikmati itu hati. 


\section{Referensi}

al-Fārābī, A. N. (1967). Kitāb al-mūsīqū al-kabīr Kairo: Dār al-kātib al-'arabī li-al-ṭibā'a wa-al-našr. Badenhausen, K. (2016, Maret 6). How Maria Sharapova Earned \$285 Million During Her Tennis Career. Dipetik September 7, 2018, dari Forbes: https://www.forbes.com/sites/kurtbadenhausen/2016/03/08/how-maria-sharapova-earned285-mill-during-her-tennis-career/

Bruner, J. S. (1993). The autobiographical process. Dalam The Culture of Autobiography: Constructions of Self-Representation (hal. 38-56). Stanford: Stanford University Press.

Darwin, C. R. (1872). The expression of the emotions in man and animals. London: John Murray.

David, B. (2014). Seductive pleasures, eluding subjectivities: some thoughts on dangdut's ambiguous identity. Dalam B. Barendregt, Sonic modernities in the Malay world: A history of popular music, social distinction and novel lifestyles (1930s-2000s) (hal. 249-268). Brill.

Davis, D. E., Hook, J. N., Jr., E. L., Tongeren, D. R., Gartner, A. L., II, D. J., et al. (2011). Relational humility: conceptualizing and measuring humility as a personality judgment. Journal of Personality Assessment, 93(3), 225-234.

Fitriya, A. (2018). Hubungan kuasa komunikasi panggung penyanyi dangdut. Interaksi Online, 6(1), $1-9$.

Fraenkel, J. R., \& Wallen, N. E. (2009). How to design and evaluate research in education (7th ed.). New York City: McGraw-Hill.

Hakim, C. (2010, Oktober). Erotic Capital. European Sociological Review, 26(5), 499-518.

Madonna (Pemain). (1989). Like a Prayer. Dalam Like a Prayer. Burbank: Warner Bros.

McNeill, R. J. (2000). Sejarah musik: musik awal sejak masa yunani kuno sampai akhir masa barok, tahun 0-1760. . Jakarta Pusat: Gunung Mulia.

Nadel, I. B. (1986). Biography: fiction, fact and form. New York City: Springer.

Prasetyo, D. A. (2012, April 11). Musik yang paling benar. Dipetik Februari 26, 2020, dari AhmadDhani.com: http://ahmaddhani.com/musik-yang-paling-benar/

Puspasari, D., \& Syaifullah, A. (2019, September 1). Stigma Pedangdut Dipandang Sebelah Mata, Wika Salim Sorot Hal Ini. Dipetik April 16, 2020, dari detikHOT: https://hot.detik.com/celeb/d-4689239/stigma-pedangdut-dipandang-sebelah-mata-wikasalim-sorot-hal-ini\#

Queen (Pemain). (1978). Bicycle race. Dalam Jazz. London: Electric and Musical Industries.

Setiawan, A. R. (2018, Maret 5). Breast Capital. Dipetik September 7, 2018, dari Alobatnic: https://alobatnic.blogspot.com/2018/03/breastcapital.html

Setiawan, A. R. (2018, Januari 1). Pantat Perekat Umat. Dipetik September 6, 2018, dari Alobatnic: https://alobatnic.blogspot.com/2018/01/pantat-perekat-umat.html

Stajkovic, A. D. (2006). Development of a core confidence-higher order construct. Journal of Applied Psychology, 91(6), 1208-1224.

Stanley, L. (1992). The auto/biographical $i$ : the theory and practice of feminist auto/biography. Manchester: Manchester University Press.

Steedman, C. (2000). Enforced narratives: stories of another self. Dalam Feminism and Autobiography: Texts, Theories, Methods (hal. 25-39). London: Routledge.

Wallach, J. (2014). Notes on dangdut music, popular nationalism, and indonesian islam. Dalam B. Barendregt, Sonic modernities in the Malay world: A history of popular music, social distinction and novel lifestyles (1930s-2000s) (hal. 271-289). Brill.

Weintraub, A. N. (2006). Dangdut soul: who are 'the people'in indonesian popular music? Asian Journal of Communication, 16(4), 411-431.

Weintraub, A. N. (2010). Dangdut stories: a social and musical history of indonesia's most popular music. Oxford: Oxford University Press.

Zein, L. F., \& Setiawan, A. R. (2019, Maret 19). Salahkah Menjadi Perempuan Cantik? Laila Academy. 